\title{
What is the Strategic Value of Investments in Alternative Local Energy Supply?
}

\author{
Gerd Küpper*
}

Katholieke Universiteit Leuven, Center for Economic Studies and K.U.Leuven Energy Institute, Belgium.

\begin{abstract}
This paper studies strategic incentives to invest in electricity generation capacity using a local fuel like renewables or coal. It shows that investing in this capacity, even if not used, improves the bargaining position of a power producing firm that also imports another fuel such as gas. When several importers are considered, the paper finds that investment has a positive strategic effect on all other importers' bargaining position. A government energy policy that forces utilities to invest in capacity based on particular fuels can be justified not only for environmental but also for strategic reasons.
\end{abstract}

JEL classification: C78, Q40, Q48, Q50.

*I am grateful for helpful comments by Stef Proost, Svetlana Ikonnikova and the members of the Energy, Transport and Environment research group at K.U.Leuven. Thanks also due to the participants of the Young Energy Economists and Engineers Seminar (Vienna, 2008) and of the Belgian Environmental Economics Day (Louvain-La-Neuve, 2009). 


\section{Introduction}

Current energy discussions frequently relate to climate change and the increasing import dependence on oil and gas. Net total gas imports of the European Union (EU27) amount to 60 percent of total EU consumption and supply is highly concentrated: Russia is the largest supplier to the European Union with a share of 40 percent of total imports, followed by Norway (23 percent) and Algeria (17 percent). ${ }^{1}$ Import dependence is expected to grow in the coming years and the establishment of the Gas Exporting Countries Forum may be the precursor of a future "Gas OPEC". „The Gas Exporting Countries Forum (GECF) is a gathering of the world's leading gas producers aimed at representing and promoting their mutual interests." Furthermore, one of its missions is to "identify and promote measures and processes necessary to ensure that Member Countries derive the most value from their gas resources, taking into consideration the nature of gas as a non-renewable source of energy."

In this context, the European Union sets ambitious targets to transform Europe into a low carbon economy with secure energy supplies. By the year 2020, not only a reduction of at least 20 percent in greenhouse gas emissions, but also a share of 20 percent of renewable energy source (RES) in EU energy consumption should be achieved (European Commission, 2008). This shows that the European Union's energy policy objective, besides more competitive energy markets, is both to slow down global warming and to protect the economy from excessive fuel import prices. High fuel prices may be the result of a major supply disruption for geopolitical or technical reasons, or of a concentrated supply favouring the exercise of market power. By increasing the share of renewables in energy consumption, the EU strives to minimize the economic impact of import price increases.

In this paper, we question whether it makes sense to foster renewable energy sources not only for environmental but also for strategic reasons. To simplify, we ignore the risk of a supply interruption for geopolitical or technical reasons and only consider the problem of a concentrated fuel supply. In this setting, it is argued that the fuel importing industry (e.g. the electricity sector) is not unaware of its import dependence but at the same time it also recognizes its ability to alter import prices. The reason is that the electricity sector is currently dominated by a few large companies such as E.ON, GDF Suez or EDF. Due to their size, these companies cannot be regarded as passive price takers in the gas market. On the contrary, we argue that they actively bargain with fossil fuel exporters over the import price. Investing in local electricity generation capacity (e.g. wind, nuclear and coal-fired

\footnotetext{
${ }^{1}$ Eurostat, yearly statistics 2006, Statistical Books 2008 Edition.

${ }^{2}$ See website of the Gas Exporting Countries Forum: http://www.gecforum.org/
} 
capacity with sufficiently differentiated sources of supply) is a way to improve the importer's bargaining position and to protect itself against excessive import prices. When several importers bargain with the same exporter, we also show that a common energy policy, like the European target of 20 percent of RES, may make sense in the presence of positive strategic spillover effects.

The remainder of this paper is organized as follows: Section 2 gives an overview of the relevant literature. Section 3 describes the players we consider in the model, namely one exporter and one importer of a fossil fuel. In Section 4, we describe the sequence of the game which is formalized in Section 5. Section 6 introduces increasing marginal supply costs. In Section 7 we explain why public intervention may be required. Section 8 extends the model to several importers and the last section concludes.

\section{Literature review}

The topic of our paper is related to three strands of literature which are briefly discussed below.

A first strand of literature considers the two-sided strategic interaction between exporters and importers of a natural resource and discusses the need for public intervention. Karp and Newbery $(1991,1992)$ derive dynamically consistent oil import tariffs to capture part of the resource rent. Wirl and Dockner (1995), Tahvonen (1996), Rubio and Escriche (2001) or Liski and Tahvonen (2004) add the stock externality problem related to harmful emissions. In this case, a carbon tax has two components: a Pigouvian component to take the externality into account, and a trade-policy, or strategic, component to capture part of the resource rent.

Our paper is different to this literature as we do not consider fuel import demand to be passive. Instead, importing firms recognize their ability to influence import prices and they bargain actively with fuel suppliers. Furthermore, we do not consider the exhaustibility of the polluting resource and the stock dimension of the environmental externality.

A second strand of literature is related to the hypothesis of Galbraith (1952) according to which concentrated downstream markets can act as a counterbalance to powerful upstream firms. This is known as „countervailing power”. Larger buyers are able to obtain lower input prices and social welfare increases if the lower input prices are passed on to consumers. This argument is often brought forward in merger cases (Inderst and Schaffer, 2008). The related literature mainly discusses the effect of the number of retailers, the mode of competition in the downstream 
market and the size of the buyers on the countervailing power. In von UngernSternberg (1996), the strategic interaction is modelled as a two-stage game. In the first stage, the single producer bargains with every retailer separately over the wholesale price. The outcome is the Nash bargaining solution, i.e. the equilibrium wholesale price rises if the producer's exogenuously given bargaining power increases or if the his outside option improves. The latter improves when the number of retailers increases. In the second stage, the retailers compete according to the Cournot or the perfect competition assumptions. In the case of Cournot competition, von Ungern-Sternberg (1996) shows that when the number of retailers decreases, the decrease of the wholesale price is always more than outweighed by an increased market power in the retail market. The countervailing power hypothesis thus only holds if competition between retailers is fierce (perfect competition). Dobson and Waterson (1997) discuss a two-stage complete information game in which an input supplier first bargains with differentiated retailers over a unit transfer price. Then retailers engage in a price-setting competition. The authors show that the bargaining power of the supplier decreases when the number of retailers shrinks, since he has fewer alternatives in case an agreement with one of the retailers fails (the outside option of the supplier is weaker). However, the total effect on the supplier's profit depends on a second effect, namely the substituability of the retailers' good. If these goods are close substitutes, competition among retailers is fierce and leads to a decrease of the final price and of the supplier's profit, but increases social welfare. Hence, competition authorities should accept highly concentrated retail markets only if the goods are close subsititutes. However, the supplier could be tempted to deal with only one retailer to avoid this second effect. While his share of the surplus would be smaller, the surplus itself would be larger. Inderst and Wey (2007) discuss two channels of buyer power. Larger buyers obtain a discount if the supplier is capacity constrained or has strictly convex costs. In the first case, a larger buyer causes a more than proportional loss to the supplier when the negotiation breaks down. In the second case, with strictly convex supply costs, a larger buyer negotiates over a wider production interval, where average incremental costs are lower. In contrast to the two previous papers, Inderst and Wey (2007) only focus on the buyer's size since buyers do not compete with each other in the downstream markets. These markets are independent and a single firm operates in each of them. The size of a buyer is defined by the number of retailing firms it owns.

Our paper is different to this literature in the sense that we consider neither competition between buyers nor the size of the buyer, since we deal with only one buyer and one market with a constant demand for electricity. Instead, the buyer 
can improve his outside option by investing in locally available or geographically unconcentrated energy sources.

Finally, our paper is related to a third strand of literature which deals with optimal portfolio theory and the real options approach applied to electricity generation (see for instance Bar-Lev and Katz [1976], Awerbuch [2006], Wickart and Madlener [2007] or Roques et al. [2008]). Electricity generation mixes are the result of a comparison of current and future expected costs and risks associated to the different technologies.

Our approach is different as we assume away uncertainty. Instead, we do not consider fuel costs as given exogenously but show that the choice of the generation mix will affect the price an importer has to pay for his fuel imports.

\section{Players}

We propose a simplified model of bilateral negotiation since the traditional market interface model, which assumes that agents interact anonymously, is less appropriate when the number of players is small. Two players are considered: a domestic electricity producer who imports an input, e.g. gas and a foreign supplier of this input. We refer to the former as importer and to the latter as exporter. The importer sells the generated electricity to consumers on his market. We assume that consumers are price-takers and have an exogeneously given demand equal to $Q$. Furthermore, consumers are willing to pay at most $\bar{P}$ for $q \leq Q$ and 0 for $q>Q$ (see figure 1 ). Later on, we will also consider a government as a strategic player which intervenes in the market to induce socially optimal outcomes.

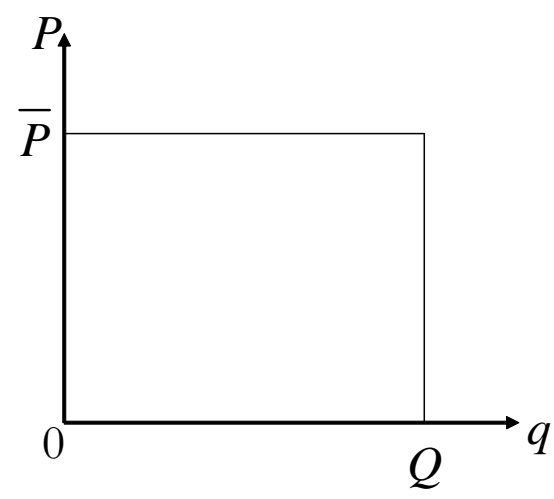

Figure 1: The demand for electricity 


\subsection{The importer}

Let the electricity generating company be a monopolist in the domestic market. Assume that to produce electricity it can use two technologies: one using a fuel that needs to be imported, denoted $f$ (,foreign"), and another using a fuel that is either locally available or geographically unconcentrated, denoted $l$. The former technology refers to gas technology and the latter technology can refer to different types of technology: renewable energy, coal but also nuclear. For the sake of clarity, we call this technology throughout the paper the „local” technology. The amount of electricity produced with the gas technology (resp. local technology) is given by $q_{f} \geq 0$ (resp. $q_{l} \geq 0$ ), i.e. total production is $q=q_{f}+q_{l}$.

In order to produce with the local technology, the importer has to build new capacities with a cost $k$ per unit of capacity and per period. The variable production cost of this technology equals $r$ per period. It does not require any input from the exporter and has an emission rate $e_{l}$ per unit of electricity produced. Total production with the local technology is limited by the installed capacity $K$ : $0 \leq$ $q_{l} \leq K$

Let the importer have capacities based on the gas technology already installed, so that capital costs are sunk. Furthermore, we assume that this technology has no capacity limit. This simplifying assumption favours the gas technology with respect to the local technology, as no investment in this technology is needed anymore. In this sense, we underestimate the incentives to invest in local technology. We assume that to produce one unit of power with the gas technology, one unit of the input has to be imported. Emissions per unit of production equal $e_{f}$.

\subsection{The exporter}

In our simplified model, we assume that there is only one exporter with the supply cost function $C\left(q_{f}\right)$, which we specify in detail further. ${ }^{3}$ The supply cost includes the extraction and the transportation cost.

\section{A dynamic game}

We begin by considering the interaction between the importer and the exporter, without governement intervention. Therefore, the environmental damage implied by emissions is not taken into consideration. The importer and the exporter negotiate

\footnotetext{
${ }^{3}$ The network-system, which is necessary to transport the resource to the importing country, exists and has no capacity limit.
} 
the terms of a supply contract, which is assumed to be complete and non-linear. The contractual terms are the transfer that the importer pays to the exporter and the amount of gas supplied to the importer. Furthermore, we avoid problems of uncertainty and asymetric information by assuming that information is complete.

The timing of the game is as follows: in the first period, the importer has the option to invest in local technology. This period is referred to as the investment period. In the second period, which we name the bargaining period, the importer and the exporter negotiate a supply contract. The game is solved backwards.

\section{Formalization}

We start by analyzing the game in the second period, when capacity $K$ of the local technology is fixed. Total supply costs of the foreign resource $C\left(q_{f}\right)$ and environmental damages $D(E)$ are linear in the quantity of electricity produced with the gas technology and in emissions: $C\left(q_{f}\right)=c q_{f}$ and $D(E)=\gamma E=\gamma\left(e_{f} q_{f}+e_{l} q_{l}\right)$. The case with a convex supply cost function will be discussed later.

\subsection{The bargaining period}

We model the bargaining game in characteristic function form. Let $N=\{i, e\}$ be the set of players, the importer and the exporter, respectively, and $\nu$ a characteristic function defined on all subsets (coalitions) $S \subseteq N$. Since we have two players in our model, two situations are to be considered: the importer and the exporter cooperate, in which case $S=N$ and is called the "grand coalition", or each player stays alone such that $S=\{i\}$ or $S=\{e\}$, which are called singletons. The value $\nu(S)$ is defined as the maximum payoff which can be achieved by members of coalition $S$. The worth of an empty set is zero $(\nu(\emptyset)=0)$ and the value function is assumed to be super-additive: $\nu(N) \geq \nu(\{i\})+\nu(\{e\})$.

To solve the game and to find how the players share the joint payoff, we use the „Shapley value” (Shapley, 1953). The Shapley value can be considered as the aggregated power of a player in his cooperation opportunities (Winter, 2002) and is defined as:

$$
\phi_{h}[\nu]=\sum_{S \subseteq N} \frac{(s-1) !(n-s) !}{n !}[\nu(S)-\nu(S \backslash h)] ; h=i, e
$$

where $s$ and $n$ are the number of players in coalitions $S$ and $N$, respectively. ${ }^{4}$

\footnotetext{
${ }^{4}$ The function $\phi$ is the unique function that simultaneously satisfies the axioms of anonymity or symmetry (players that are identically treated by the value function $\nu$ get the same Shapley value),
} 
If the exporter decides not to cooperate, then his payoff is zero. The importer, however, has a positive stand-alone payoff if he invests in local technology. Then, he can produce (and sell) electricity and earn a positive profit. However, his production is limited by the capacity $K$ installed in the investment period. Given our assumption that electricity demand and $\bar{P}$ are fixed, the importer sets the monopoly electricity price $P=\bar{P}$ and the consumer surplus $(\bar{P}-P) q$ is zero. We obtain the following values of the characteristic function:

$$
\begin{aligned}
\nu(\{e\} ; K) & =0 \\
\nu(\{i\} ; K) & =\max _{q_{l}}\left[\begin{array}{c}
\left.\bar{P} q_{l}-r q_{l}\right] \\
\text { s.t. } q_{l} \leq K
\end{array}\right.
\end{aligned}
$$

Equation (3) gives the stand-alone payoff of the importer, which is $(\bar{P}-r) K$ if $K<Q$ and $(\bar{P}-r) Q$ if $K \geq Q$. Note that this stand-alone payoff increases for a higher parameter $K$.

When players stay together, they maximize their joint payoff so that the worth of the grand coalition equals

$$
\nu(N ; K)=\max _{q_{l}, q_{f}}\left[\bar{P}\left(q_{f}+q_{l}\right)-c q_{f}-r q_{l}\right]
$$

We distinguish two cases (see Appendix):

Case 1: the gas technology has a higher variable cost and the capacity of the local technology is entirely used to produce electricity $(\mathbf{c}>\mathbf{r})$ :

$$
\begin{aligned}
& q_{l}^{*}=\min [Q, K] ; \\
& q_{f}^{*}=\max \left[0, Q-q_{l}^{*}\right] .
\end{aligned}
$$

A larger capacity $K$ relaxes the constraint in (4) and increases the joint payoff.

Case 2: the local technology has a higher variable cost and is, therefore, not used at all $(\mathbf{c} \leq \mathbf{r})$. This result relies on our assumption of unconstrained supply and production capacity based on the gas technology:

$$
\begin{aligned}
& q_{l}^{*}=0 ; \\
& q_{f}^{*}=Q .
\end{aligned}
$$

efficiency (the sum of the Shapley values for all players equals the value of the grand coalition) and additivity (when two independent games $\nu$ and $\sigma$ are combined, their Shapley values are added for each player). For a proof, see Shapley (1953). Although the Shapley value is a solution concept originating from cooperative game theory, it can also arise as an equilibrium outcome in noncooperative frameworks (see, for instance, Pérez-Castrillo and Wettstein, 2001). For a simple interpretation of the Shapley value, see Rapoport (1970, p.106). 
The constraint in (4) is not binding and a higher parameter $K$ has no impact on the joint payoff. However it always improves the stand-alone value as long as $K<Q$.

So far, we have determined the value function $\nu(S ; K)$ for every coalition $S \subseteq N$. We now compute the Shapley value for both players, as in (1), and interprete the results. For a game with two players, the Shapley value reduces to ${ }^{5}$ :

$$
\phi_{h}(K)=\frac{1}{2} \nu(N ; K)+\frac{1}{2}[\nu(\{h\} ; K)-\nu(N \backslash h ; K)] ; h=i, e .
$$

Equation (7) indicates that the value of the grand coaliton $\nu(N ; K)$ is divided between the importer and the exporter depending on their stand-alone payoff $\nu(\{h\} ; K)$. In particular, the importer's bargaining position is improved by a larger local technology capacity $K$. If the local technology has a lower variable cost $(\mathbf{c}>\mathbf{r})$, it increases both the joint payoff and the stand-alone payoff. If the variable cost is higher $(\mathbf{c} \leq \mathbf{r})$, it only increases the stand-alone payoff (see equations (3) and (4)). Therefore, local capacity may be unused but not useless as it has a threatening role. However, the importer has to balance this benefit with the increased investment cost. This is investigated below.

\subsection{The investment period}

The previous section showed that the importer gets a better bargaining position if he invests in local technology. However, a better outside option is costly. These two effects have to be balanced in the investment stage. The importer's investment $K$ in renewable energy technology differs in the two cases we depicted in the previous section.

\section{Case 1: The local technology has a lower variable cost $(c>r)$. The importer knows that the capacity $K$ is fully used.}

The maximization problem is thus

$$
\max _{K}\left[\phi_{i}(K)-k K\right]
$$

where the first term is the importer's share in the joint profit as stated in (7) and the second term gives the investment cost. Knowing the optimal production mix

\footnotetext{
${ }^{5}$ The Appendix provides all steps that are necessary to compute the values.
} 
given in (5), we rewrite (8) and obtain

$$
\max _{K}\left[\frac{1}{2}[\underbrace{\bar{P} Q-r K-c(Q-K)}_{\nu(N, K)}]+\frac{1}{2}[\underbrace{(\bar{P}-r) K-0}_{\nu(\{i\}, K)-\nu(\{e\})}]-k K\right] .
$$

The marginal effect of investing in capacity equals

$$
\begin{aligned}
\frac{d\left(\phi_{i}(K)-k K\right)}{d K} & =\frac{1}{2} \frac{d \nu(N, K)}{d K}+\frac{1}{2} \frac{d(\nu(\{i\}, K)-\nu(\{e\}, K))}{d K}-\frac{d(k K)}{d K} \\
& =\frac{1}{2}(c-r)+\frac{1}{2}(\bar{P}-r)-k .
\end{aligned}
$$

As shown in (10), investing in an additional unit of local capacity has three effects: it increases the joint payoff $\nu(N, K)$ by replacing expensive generation by cheaper generation. For a given sharing, this additional payoff is divided equally among the players and every player thus gets $(c-r) / 2$. The second effect is that the importer's relative outside option $\nu(\{i\}, K)-\nu(\{e\})$ improves by the amount $(\bar{P}-r)$, which increases the Shapley value of the importer by $(\bar{P}-r) / 2$. In other words, the importer not only increases the cake but also his share of the cake. These two effects are to be compared with the third effect, that is the investment cost $k$ of an additonal unit of local capacity.

Since we assume a linear cost structure, these three effects are constant and we obtain a corner solution: if the local technology has a low cost, i.e. $r+k<$ $(\bar{P}+c) / 2$, then the importer invests in this technology such that all electricity is produced with this technology: $K^{*}=Q$ and $q_{l}^{*}=q=Q$. In the other case, when $r+k \geq(\bar{P}+c) / 2$, nothing is invested in the local technology, i.e. $q_{f}^{*}=q=Q$.

\section{Case 2: The gas technology has a lower variable cost $(c \leq r)$. The im- porter knows that the local technology will not be used.}

The maximization problem of the importer is the same as stated in (8). However, in this second case the production mix $\left(q_{f}^{*}, q_{l}^{*}\right)$ is different and given by (6). By rewriting (8) we get

$$
\max _{K}\left[\frac{1}{2}[\underbrace{(\bar{P}-c) Q}_{\nu(N, K)}]+\frac{1}{2}[\underbrace{(\bar{P}-r) K-0}_{\nu(\{i\}, K)-\nu(\{e\})}]-k K\right]
$$

and the marginal effect of investing in renewable energy capacity is 


$$
\begin{aligned}
\frac{d\left(\phi_{i}(K)-k K\right)}{d K} & =\frac{1}{2} \frac{d \nu(N, K)}{d K}+\frac{1}{2} \frac{d(\nu(\{i\}, K)-\nu(\{e\}))}{d K}-\frac{d(k K)}{d K} \\
& =0+\frac{1}{2}(\bar{P}-r)-k .
\end{aligned}
$$

Contrary to the previous case, investing in additional capacity only has two effects: it increases the importer's share of the joint payoff $\nu(N)$ by $(\bar{P}-r) / 2$ and it costs $k$ per unit. However, the joint payoff cannot be increased since the local technology has the higher variable cost and will thus never be used. Therefore, the size of the cake does not change but the importer can increase his share of it.

As in Case 1, we obtain corner solutions for investment: if the investment cost of the local technology is sufficiently low $(r+2 k<\bar{P})$, then the importer invests a maximum in this technology, although it will not be used: $K^{*}=Q$ and $q_{f}^{*}=q=Q$. The local technology has a purely strategic use. In the other case $(r+2 k \geq \bar{P})$, nothing is invested in the local technology $\left(K^{*}=0\right)$.

\section{$5.3 \quad$ Summing up}

The linear case shows that there are only corner solutions. Either no investment takes place or all the electricity demand can be satisfied with local capacity. The actual electricity production "mix" can be different: the local technology can be fully used or not used at all.

The joint payoff $\nu(N)$ is shared between the players according to the Shapley values $\phi_{e}$ and $\phi_{i}$. The joint payoff equals the total revenue the importer receives in the electricity market minus total costs: $\nu(N)=\bar{P} Q-q_{f}^{*} c-q_{l}^{*} r$. The contractual terms, namely the transfer $\left(\phi_{e}+c q_{f}^{*}\right)$ that the importer pays to the exporter and the amount of gas $q_{f}^{*}$ supplied to the importer, follow from the discussion above.

Instead of considering the sharing of the surplus according to the Shapley values $\phi_{h}$, it is useful to analyze the results in terms of the implied per unit gas price $\widehat{c}$. This price is such that the exporter's revenue minus the supply cost equals his share of the total surplus:

$$
q_{f}^{*}(\widehat{c}-c)=\phi_{e}
$$

If no investment in local technology took place $(K=0)$, electricity production is only based on gas and the surplus $\nu(N)$ is shared equally. The price per unit of gas equals $\widehat{c}_{K=0}=(\bar{P}+c) / 2$. There is mutual dependence since the exporter needs the access to the market but on the other hand, the importer depends on resource imports. However, if the cost of the local technology is low $(r+2 k<\bar{P})$, it makes 
sense to invest in this technology even though it will not be used since $c<r$. The price per unit of gas is lower than in the previous case $\left(\widehat{c}_{K=Q}=(r+c) / 2\right)$ since the importer can threat to fall back on his own capacity, which seems to be overbuilt and underused. The importer will be completely independent of imports if the local technology has a lower variable cost $(c>r)$ and if the total cost is relatively low $(r+k<(\bar{P}+c) / 2)$.

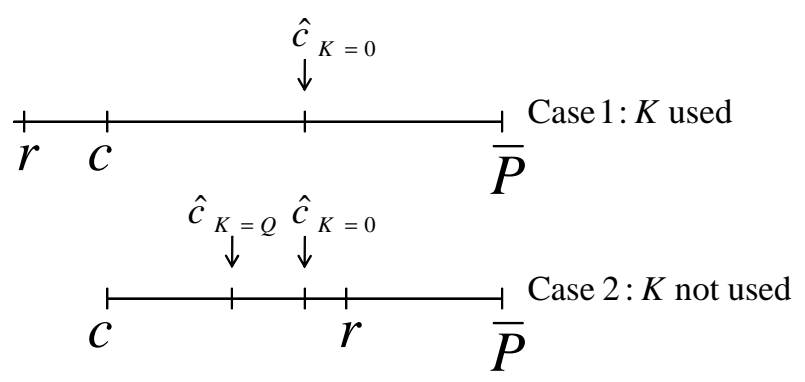

Figure 2: The gas price when the marginal gas supply cost is constant

The next section looks at the non-linear case where the supply cost $C\left(q_{f}\right)$ is a convex function.

\section{The non-linear case}

We assume that the total supply cost of gas is convex, i.e. $C\left(q_{f}\right)=c q_{f}^{2}$. Since we consider at the moment only the problem of the importer, without any government intervention, the environmental damage is not considered yet in the optimal decision of the importer.

\subsection{The bargaining period}

Like in section 5.1, the importer and the exporter define the optimal production $\operatorname{mix}\left(q_{f}^{*}, q_{l}^{*}\right)$ that maximizes the joint surplus for a given capacity $K$. The optimal production mix depends on a critical capacity limit $\bar{K}$ (see Appendix) and is as follows:

$$
\begin{aligned}
& K \leq \bar{K}=Q-\frac{r}{2 c} \Rightarrow\left(q_{l}^{*}, q_{f}^{*}\right)=(K, Q-K) \\
& K>\bar{K}=Q-\frac{r}{2 c} \Rightarrow\left(q_{l}^{*}, q_{f}^{*}\right)=(\bar{K}, Q-\bar{K})
\end{aligned}
$$

This situation is represented in the figure below. The gas technology is used as long as its marginal production cost $2 c q_{f}$ is lower than the marginal production cost 
of the local technology $r$. The critical capacity limit $\bar{K}$ is obtained by equalizing marginal production costs of both technologies: $2 c(Q-\bar{K})=r$.

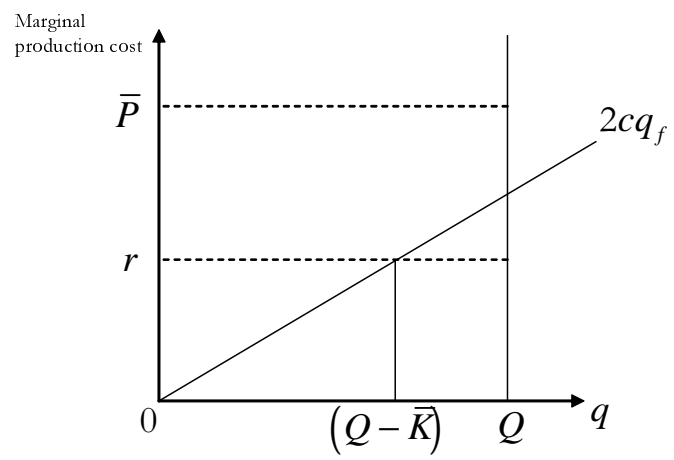

Figure 3: The optimal production mix

Note that the stand-alone values $v(\{e\})$ and $v(\{i\})$ are derived in the same way as in the linear case before.

\subsection{The investment period}

The importer knows that the capacity will be fully used as long as it remains below the threshold $\bar{K}$. Capacity above this threshold will not be used for producing electricity but it may be useful to improve the bargaining position of the importer. We consider these cases below.

\section{Case 1: The local capacity is binding $(\mathrm{K} \leq \overline{\mathbf{K}})$.}

The maximization problem reads

$$
\max _{K}\left[\phi_{i}(K)-k K\right] .
$$

We rewrite the problem according to (1) and (12) and obtain

$$
\max _{K}[\frac{1}{2} \underbrace{\left[\bar{P} Q-r K-c(Q-K)^{2}\right]}_{\nu(N)}+\frac{1}{2} \underbrace{[(\bar{P}-r) K]}_{v(\{i\})-v(\{e\})}-k K] .
$$

The effect on the importer's surplus of an additional unit of capacity is

$$
\begin{aligned}
\frac{d\left(\phi_{i}(K)-k K\right)}{d K} & =\frac{1}{2} \frac{d \nu(N)}{d K}+\frac{1}{2} \frac{d(\nu(\{i\})-\nu(\{e\}))}{d K}-\frac{d(k K)}{d K} \\
& =\frac{1}{2}(2 c(Q-K)-r)+\frac{1}{2}(\bar{P}-r)-k
\end{aligned}
$$


As long as the capacity is below the critical threshold $\bar{K}$, producing with the local technology is cheaper. Hence, investing in one additional unit of capacity reduces total production costs and increases the joint surplus by $2 c(Q-K)-r$. Besides an increase of the joint surplus, it also directly increases the importer's Shapley value by $(\bar{P}-r) / 2$. The investment cost of an additional unit of capacity equals $k$. The optimal investment decision depends on the relative importance of these three effects:

$$
\begin{aligned}
& r+2 k>\bar{P} \Rightarrow K^{*}=\bar{K}+\frac{1}{c}[1 / 2(\bar{P}-r)-k] \leq \bar{K} \\
& r+2 k \leq \bar{P} \Rightarrow K^{*}=\bar{K}
\end{aligned}
$$

The situation described by (15) (resp. (16)) is referred to as the „high-cost technology” (resp. „low-cost technology”).

Case 2: The local capacity is not binding $(\mathbf{K}>\overline{\mathbf{K}})$. The importer has the objective

$$
\max _{K}\left[\phi_{i}(K)-k K\right]
$$

and by (1) and (13) we get

$$
\max _{K}[\frac{1}{2} \underbrace{\left[\bar{P} Q-r \bar{K}-c(Q-\bar{K})^{2}\right]}_{\nu(N)}+\frac{1}{2} \underbrace{[(\bar{P}-r) K]}_{v(\{i\})-v(\{e\})}-k K] .
$$

Investing in local technology capacity has two effects:

$$
\begin{aligned}
\frac{d\left(\phi_{i}(K)-k K\right)}{d K} & =\frac{1}{2} \frac{d \nu(N)}{d K}+\frac{1}{2} \frac{d(\nu(\{i\})-\nu(\{e\}))}{d K}-\frac{d(k K)}{d K} \\
& =0+\frac{1}{2}(\bar{P}-r)-k .
\end{aligned}
$$

The investment no longer increases the joint surplus but the importer can still improve his outside option. Whether he invests more than the critical threshold $\bar{K}$ depends on the cost of the local technology and the electricity price consumers are willing to pay:

$$
\begin{aligned}
& r+2 k>\bar{P} \Rightarrow K^{*}=\bar{K} \\
& r+2 k \leq \bar{P} \Rightarrow K^{*}=Q
\end{aligned}
$$


Combining the results in (15) to (18), we conclude that if the local technology is high-cost, the importer invests $K_{1}^{*}=\bar{K}+\frac{\bar{P}-r-2 k}{2 c}<\bar{K}$ in this technology and the capacity is fully used. ${ }^{6}$ Some electricity is produced with the gas technology: $q_{f}^{*}=Q-K^{*}$. If, however, the local technology is low-cost, the importer invests $K_{2}^{*}=Q$ in renewable energy technology. In this case, electricity is produced with both technologies and some of the local capacity is unused: $q_{l}^{*}=\bar{K}$ and $q_{f}^{*}=Q-\bar{K}$.

These results are summarized in Figure 4. The vertical axis on the right-hand side gives the profit of the importer, i.e. the bargaining surplus minus the investment cost. The horizontal axis indicates the installed capacity of the local technology. The left-hand vertical axis gives the capacity which is effectively used to produce electricity. The dashed curves then give the importer's profit in function of the installed capacity. If technology is low-cost, the importer's profit function is monotonously increasing and the importer maximizes his total profit by installing a capacity equal to $Q$ (corner solution for investment). By contrast, if technology is high-cost, the maximum is achieved for a capacity below the critical threshold $\bar{K}$ (interior solution for investment). The bold continuous line shows that a capacity below $\bar{K}$ is always fully used (see $45^{\circ}$ line) while the capacity exceeding $\bar{K}$ is not used to produce electricity, independent of whether the technology is high-cost or low-cost. The capacity exceeding $\bar{K}$ only has a strategic value.

Note that while we call a technology "low-cost”, the importer's profit $\phi_{i}(K)-k K$ is not necessarily higher than in the "high-cost" situation (in the figure below, the profit is higher in the low-cost case). The distinction refers to the relationship between variable and fixed costs and it defines the optimal investment and the optimal generation mix. Below, we give a very rough idea of „local” technologies in which it is more interesting for an importer to invest.

\footnotetext{
${ }^{6}$ For $K_{1}^{*}>0$, it is required that $2(r+k)<\bar{P}+2 c Q$. Otherwise, $K_{1}^{*}=0$.
} 


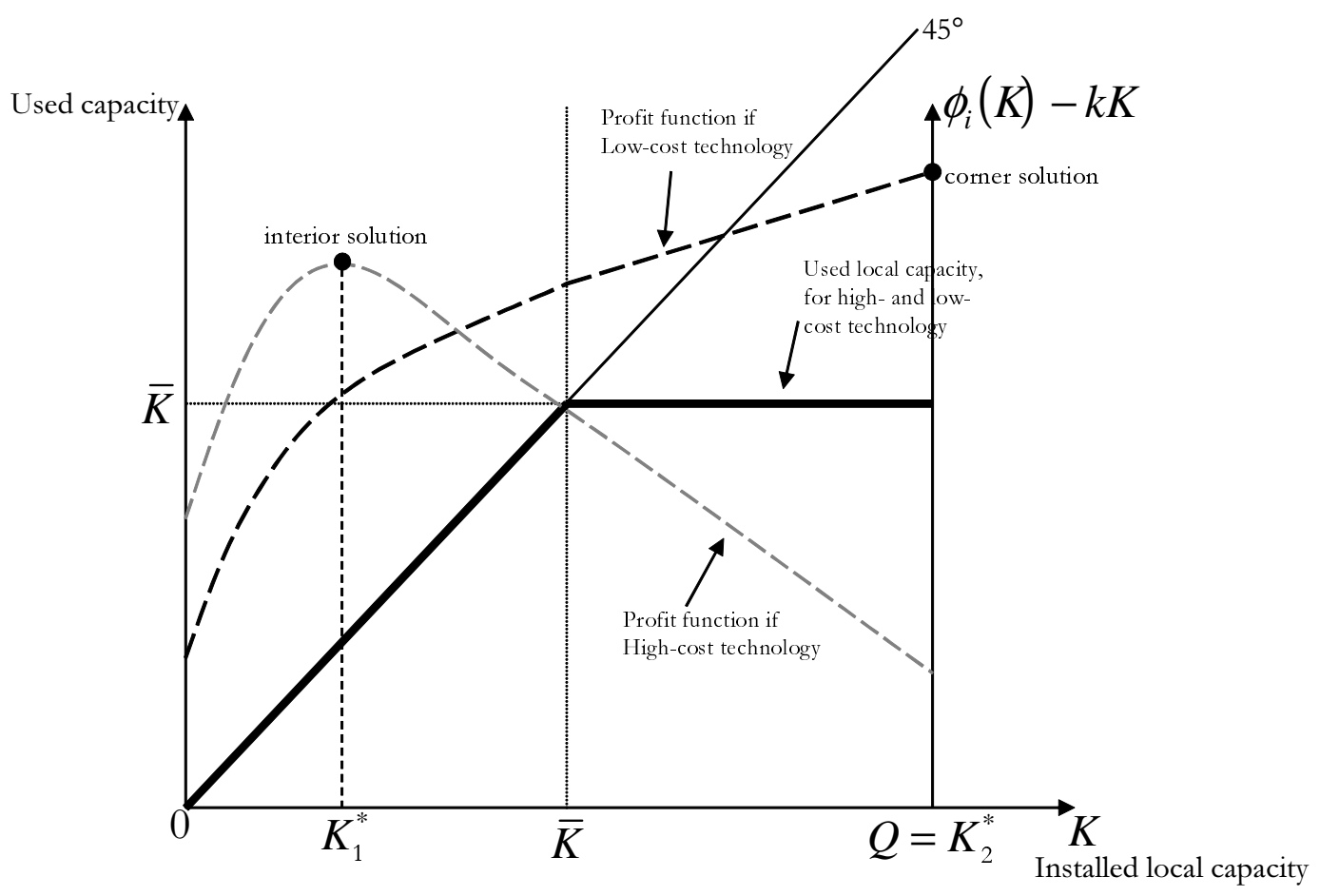

Figure 4: The optimal investment decision

\subsection{Summing up}

The main results of the linear case carry over to the situation with increasing marginal supply costs. For a costly local technology, only some investment is realized and this capacity is fully used (interior solution, see Figure 4 above). For the remaining electricity demand that cannot be satisfied with the local capacity, the surplus is shared equally between the importer and the exporter given their mutual dependence. For a relatively cheap technology, some capacity remains unused, but it is not useless since it enables the importer to obtain lower gas prices.

The price per unit of gas decreases the more the importer invests in local capacity, independent of whether the local technology is high- or low-cost. If the capacity is small $(K \leq \bar{K})$, the gas price equals

$$
\begin{aligned}
\widehat{c}_{K \leq \bar{K}} & =(c(Q-K)+\bar{P}) / 2 \\
& =(\text { average supply cost }+ \text { mean revenue }) / 2
\end{aligned}
$$

while for a large capacity $(K>\bar{K})$, the gas price is

$$
\widehat{c}_{K>\bar{K}}=(c(Q-\bar{K})+\alpha \bar{P}+\beta r) / 2
$$


where $0 \leq \alpha=\frac{Q-K}{Q-\bar{K}} \leq 1$ and $0 \leq \beta=\frac{K-\bar{K}}{Q-\bar{K}} \leq 1$. Both $\widehat{c}_{K \leq \bar{K}}$ and $\widehat{c}_{K>\bar{K}}$ are decreasing in $K$ and this decrease is monotonous over the interval $[0, Q]$. Again, a lower gas price has to be compared with the variable cost of the local technology that replaces gas capacity (for $K \leq \bar{K}$ ) and with the investment cost of an additional unit of local capacity $(\forall K \in[0, Q])$.

Finally, technologies likely to be used as a threat are those which satisfy $2 k+r<$ $\bar{P}$ (low-cost technologies), i.e. technologies with a relatively low investment cost compared to the variable cost. Therefore, we expect that coal is more likely to remain partly unused rather than nuclear or wind technology.

\subsection{Numerical illustration}

Table (1) gives the total cost, i.e. the investment cost per $M W h$ and the fuel cost per $M W h$, for various local technologies. ${ }^{7}$ For a willingness to pay $\bar{P}$ of about $70 E U R / M W h$, coal and nuclear are low-cost technologies while wind power is a high-cost technology according to our model. Therefore, we expect that if there is investment in coal- or nuclear-fired capacity, there will be more capacity than what is used to produce electricity, while wind power capacity will be used as much as possible. We also report $\mathrm{CO}_{2}$ emissions, even though the importer does not take them into account. Emission rates are as follows: $e_{f}=e_{\text {gas }}=0.36 t / M W h$, $e_{l}=e_{\text {nuclear }}=e_{\text {wind }}=0 t / M W h$ and $e_{l}=e_{\text {coal }}=0.86 t / M W h($ IEA, 2005).

\footnotetext{
${ }^{7}$ The cost data is based on IEA (2005). The data covers plants under construction or planned and that could be commissioned between 2010 and 2015 in the countries participating in the study (18 OECD and 3 non-OECD countries). Costs are reported in July 2003 Euro and discounted to January 2010. The values we report in the illustration are representative. Regarding the investment cost $k$, a lifetime of 40 years is assumed for coal and nuclear technology. The lifetime of wind power is assumed to be 20 years. A discount rate of $10 \%$ was applied. Note that the investment cost takes the technical availability of the technologies into account. For coal and nuclear capacity, an availability of $85 \%$ is assumed while for (onshore) wind power, the availability ranges between 17 and $38 \%$. The capacity is therefore expressed in effective $M W$, as if the availability equals $100 \%$. Since availability is below $100 \%$, the installed capacity is higher. We omit O\&M costs.
} 


\begin{tabular}{|l|c|c|c|}
\hline$E U R / M W h$ & coal & nuclear & wind \\
\hline \hline investment cost $k$ & 20 & 30 & 65 \\
\hline variable cost $r$ & 18 & 4 & 0 \\
\hline$r+2 k$ & 58 & 64 & 130 \\
\hline technology type for $\bar{P}=70$ & „low-cost” & „low-cost” & „high-cost” \\
\hline critical capacity $\bar{K}$ & $279570 M W$ & $314570 M W$ & $324570 M W$ \\
\hline investment $K^{*}$ & $Q$ & $Q$ & 174570 \\
\hline importer's payoff $\phi_{i}(K)-k K^{*}$ & $10.59 \times 10^{6}$ Euro & $11.7 \times 10^{6}$ Euro & $3.87 \times 10^{6}$ Euro \\
\hline import dependence $q_{f} / Q$ & $13 \%$ & $3 \%$ & $46 \%$ \\
\hline negotiated gas price $\hat{c}$ & 13,5 & 3 & 50 \\
\hline $\mathrm{CO}_{2}$ emissions & $256630 t C \mathrm{O}_{2}$ & $3600 t C \mathrm{O}_{2}$ & $54000 t C \mathrm{O}_{2}$ \\
\hline
\end{tabular}

Table 1: total cost of local technologies

Cost data based on IEA (2005).

We also try to know in which of the three main local technologies (coal, nuclear or wind) the importer will invest. As we mentioned earlier, a low-cost technology (coal or nuclear) is not necessarily the technology that maximizes the profit of the importer.

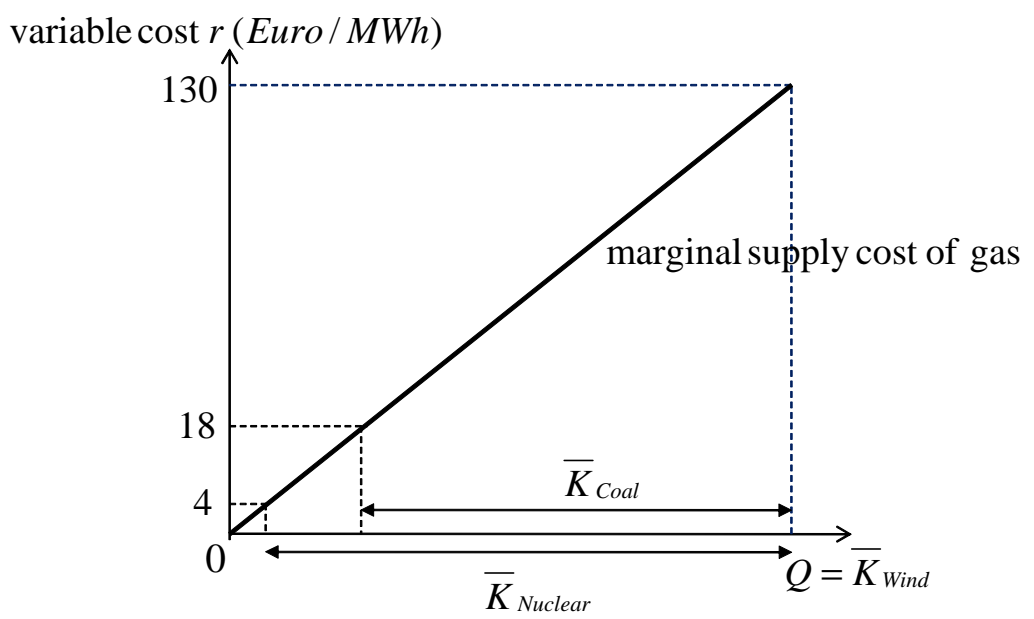

Figure 5: Variable cost and critical capacity

We apply our simplified model to the European (EU27) electricity market and set $Q=324570 M W h$ per hour ${ }^{8}$ and $c=0.0002$ (arbitrary choice). As mentioned earlier, coal and nuclear based technologies are low-cost technologies in the present example. However, unused capacity is small since the critical capacities are fairly high. Recall that the critical capacity is such that the marginal cost of the local technology equals the marginal supply cost of gas. Since the variable cost of coal

\footnotetext{
${ }^{8}$ The average hourly EU27 electricity demand is based on 2007 data provided by Eurostat. This is the most recent data available and it comprises electricity consumption from the industry, the transport sector and households.
} 
and nuclear based electricity production is low, only a small fraction of demand is satisfied with gas based production (see figure 5). Wind capacity has a too high fixed cost component to be used as a threat. Consequently, investment in wind capacity is lower than in coal or nuclear capacity and it is fully used.

From the importer's point of view, it is more interesting to invest in nuclear technology than in coal technology, although the difference is not significant. ${ }^{9}$ With nuclear capacity, the electricity demand is largely satisfied with production based on local capacity. Accordingly, the import dependence is low which means that the economy is protected against unforseen gas price shocks that might happen. $\mathrm{CO}_{2}$ emissions are low too. However, the problem of nuclear waste is not taken into account. Investing in wind power does not seem to be an interesting option because of its high investment cost. The importer's payoff is low and the economy remains largely dependent on gas imports (46\%), which can inherently lead to security of supply problems. While the emission rate of wind power is zero, emissions are not as low as with nuclear capacity as a large part of demand (46\%) is satisfied with gas based production.

The negotiated gas price depends on the available local capacity (see Section 6.3). The higher the investment in local capacity, the lower the gas price as average marginal supply costs decrease. The actual share of gas in the EU27 total generation mix is 21 percent meaning that 79 percent are satisifed with „local” capacity. If we assume that there is only one supplier as in our model and that local capacity is fully used, we may expect a gas price $\hat{c}$ of about $42 E$ uro/ $M W h$, which is close to what we observe.

Clearly, this is only a rough idea of what can happen since in reality other aspects play a role as well (the load duration profile, availability of space, construction time, public opposition to nuclear power or to $\mathrm{CO}_{2}$ intensive technologies, etc.).

\section{Public intervention}

We now consider a government that aims to improve the social welfare of the importer's country. In this paper, public intervention in the economy can be justified for two reasons: strategic considerations and market failures. They are discussed below.

\footnotetext{
${ }^{9}$ The profitability of a technology 1 compared to a technology 2 is not only determined by the total cost $k_{i}+r_{i}$. If both technologies are low-cost, technology 1 gives a higher profit than technology 2 if $8 c Q\left[\left(k_{1}+r_{1}\right)-\left(k_{2}+r_{2}\right)+\left(r_{1}^{2}-r_{2}^{2}\right)>0\right]$. If both technologies are high-cost, the condition becomes: $4\left[\left(k_{1}+r_{1}\right)-\left(k_{2}+r_{2}\right)\right]\left[\left(k_{1}+r_{1}\right)+\left(k_{2}+r_{2}\right)-\bar{P}-2 c Q\right]$. If technology 1 is low-cost while technology 2 is high-cost, the condition is: $4\left(k_{2}+r_{2}\right)\left[P-\left(k_{2}+r_{2}\right)\right]+8 c Q\left[\left(k_{2}+r_{2}\right)-\left(k_{1}+r_{1}\right)\right]>$ $\bar{P}^{2}+8 k_{2} r_{2}-r_{1}^{2}$.
} 


\subsection{Strategic motives}

Intervention may be required to shift surplus from the exporter to the importer's country. This is discussed hereafter.

In the context of one single importer, setting a per unit tax on gas increases the social welfare of the importing country. We assume that the government sets the $\operatorname{tax} \tau$ first, before the importer invests and bargains with the exporter. The government's objective is to maximize social welfare $W$, which is the sum of the consumer surplus, the importer's Shapley value minus investment costs, and tax revenues:

$$
\operatorname{Max}_{\tau} W(\tau)=\underbrace{C S}_{\text {consumer surplus }}+\underbrace{\phi_{i}(K(\tau))-k K(\tau)}_{\text {importer's payoff }}+\underbrace{\tau q_{f}(K(\tau))}_{\text {tax revenue }}
$$

The optimal tax equals

$$
\begin{array}{r}
\tau^{*}=\frac{r}{3} \quad \text { if } \quad \bar{P}-r-2 k>0 \\
\tau^{*}=\frac{2(k+r)-\bar{P}}{3} \quad \text { if } \quad \bar{P}-r-2 k \leq 0
\end{array}
$$

and is an increasing function of the cost of the local technology. Setting a tax or investing in local capacity are thus substitutes in capturing a larger share of the surplus $\nu(N)$. If the local technology is costly (high variable and/or fixed cost), the bargaining power of the importer is reduced and a tax compensates for this reduced bargaining power. On the other hand, if the local technology is cheap, the importer has a strong bargaining position and he captures already a large share of the total surplus through investment in local capacity. However, equation (19) assumes that 1 Euro received by the importer is equivalent to 1 Euro received by the citizens of the importing country through tax revenues. If the government puts less weight on the importer's payoff and more on the citizens' welfare, the optimal tax would be higher.

To raise a tax is the only instrument that makes sense in the setting without externalities. Imposing a minimum level of local capacity does not alter the investment since the objective of the importer (equation (14)) and of the government are identical. Subsidizing investment, on the other hand, can change the investment decision. If the government subsidizes investment with $s$ per unit of capacity, the investment condition becomes $\bar{P}-r-2(1-s) k \gtrless 0$. If investment is not influenced by the subsidy, i.e. if $\bar{P}-r-2 k>0$, there is a pure transfer from the taxpayers of the importing country to the importer. If $\bar{P}-r-2 k<0$, the subsidy reduces 
social welfare because of an overinvestment in local capacity. The objective of the government is

$$
\begin{aligned}
\operatorname{Max}_{s} W(s) & =\underbrace{C S}_{\text {consumer surplus }}+\underbrace{\phi_{i}(K(s))-k(1-s) K(s)}_{\text {importer's payoff }}-\underbrace{s K(s)}_{\text {subsidy expenditure }} \\
& =\phi_{i}(K(s))-k K(s)+s K(s)-s K(s)
\end{aligned}
$$

which is maximized by setting $s=0$. The objective function is identical to the importer's objective function described by (8). There is thus no reason to change investment through an investment subsidy as the importer already optimally balances higher investment costs with an improved bargaining position.

\subsection{Market failures}

Market failures prevent an efficient resource allocation. Potential sources of market failures include market power and externalities. A firm with market power typically sets a quantity such that the price is above the marginal cost, which is inefficient. In our setting with a monopolistic electricity supplier, output is not withheld because of a constant demand with a maximum willingness to pay. The market failure we consider in this section is the externality implied by harmful $\mathrm{CO}_{2}$ emissions. ${ }^{10}$

\subsubsection{A negative externality: $\mathrm{CO}_{2}$ emissions}

In the absence of any public intervention, the environmental damage caused by production-related emissions is not taken into account by the source of pollution and therefore represents a negative externality. This is not different in our setting. The importer invests in local technologies to improve his bargaining power, while he ignores the environmental damage. Therefore, considering social welfare of the

\footnotetext{
${ }^{10}$ Note that we consider only distortions within the importing country. However, we can easily check that investment decisions are sub-optimal from a global welfare point of view, i.e. when the welfare of the importing and the exporting country are considered together. In the ideal situation, the importer and the exporter choose the technology mix so as to maximize their joint surplus. Hence, there is no strategic reason to invest in local technologies. In particular, capacity never remains unused. If we consider the case of convex costs, the maximization problem would be$$
\underset{K}{\operatorname{Max}}\left[\bar{P} Q-c(Q-K)^{2}-r K-k K\right]
$$

and the optimal capacity not considering the environmental damage is equal to

$$
K^{*}=Q-\frac{r+k}{2 c}
$$

which is lower than the optimal capacity levels when strategic considerations are taken into account (as long as $\bar{P}>r+k$ ). Strategic considerations lead to an overinvestment in local technology from a global welfare point of view.
} 
importing country, we expect that investment in local technologies is suboptimal and public intervention is needed. ${ }^{11}$ We assume that the exporter places the responsibility for environmental protection on the importer's country where pollution takes place. This is a realistic assumption since as long as the resource is only traded, no pollution takes place. ${ }^{12}$

\subsubsection{Comparing instruments}

Let the government of the importing country be a strategic player, who maximizes the social surplus $W$, including the consumer surplus and the profit of the importer. We assume that the government takes the environmental damage originating from emissions $E$ into account. The emissions are assumed to be proportional to the amount of electricity produced with each technology, i.e. $E=e_{f} q_{f}+e_{l} q_{l}$. The environmental damage is a linear function of emissions: $D(E)=\gamma E$. Obviously, the emission rates $e$ are technology dependent. If the resource to be imported is gas, then $e_{f}>e_{l}$ if the local resource is wind or nuclear energy. On the other hand, if we consider coal as a local resource, then $e_{f}<e_{l}$.

We restrict our analysis to two instruments: a tax on emissions and a subsidy for wind power. They cover the main policies currently applied within the European Union: emissions are taxed through the European Union Greenhouse Gas Emission Trading Scheme (EU ETS) and RES technologies are locally supported through feedin tariffs or green certificates systems. The timing goes as follows: the government moves first and sets an emission tax $\tau$ or a wind power subsidy $s$ to maximize the social welfare of the importing country. Then, for a given policy choice, the importer invests in local capacity and thereafter negotiates a supply contract with the exporter. The game is solved backwards.

The government not only takes the environmental damage, but also the effect on the importer's bargaining position into account. The government's objective is:

$$
\operatorname{Max}_{\tau} W(\tau)=\underbrace{C S}_{\text {consumer surplus }}+\underbrace{\phi_{i}(K(\tau))-k K(\tau)}_{\text {importer's payoff }}-\underbrace{D(E(K(\tau)))}_{\text {environmental damage }}+\underbrace{\tau E(K(\tau))}_{\text {tax revenue }}
$$

if the policy is taxing emissions and

\footnotetext{
${ }^{11}$ Investment in local technology is expected to be too high compared to the socially optimal level if, instead of wind or nuclear technologies, we consider coal-fired capacity, of which emission level per unit of electricity produced is higher compared to gas-fired capacity. Considering nuclear energy as an alternative, the problem of nuclear waste should be taken into account.

${ }^{12}$ Under the Kyoto protocol, for instance, industrialized countries agreed upon reducing their emissions on average by 5.2 percent between 2008-2012 with respect to the emission level of 1990 .
} 


$$
\operatorname{Max}_{s} W(s)=\underbrace{C S}_{\text {consumer surplus }}+\underbrace{\phi_{i}(K(s))-k K(s)}_{\text {importer's payoff }}-\underbrace{D(E(K(s))}_{\text {environmental damage }}-\underbrace{s q_{l}(K(s))}_{\text {subsidy expenditure }}
$$

if wind power is subsidized.

Recall that in our setting, the consumer surplus is always zero since the importer sets the profit maximizing price for electricity, i.e. $P=\bar{P}$. Comparing analytically the different instruments and technologies is not straightforward. Therefore, we limit the comparison to a numerical illustration.

\subsubsection{Numerical illustration}

We take the same parameter assumptions as in Section 6.4. The constant marginal environmental damage is set to $\gamma=20 E U R / t C O_{2}$ (European Commission, 1999). Results are reported in the table below. ${ }^{13}$ We also indicate whether outcomes increase $(\uparrow)$ or decrease $(\downarrow)$ with respect to the situation without government intervention and without damage implied by $\mathrm{CO}_{2}$ emissions (Table 1 ).

\begin{tabular}{|c|c|c|c|c|}
\hline policy & \multicolumn{3}{|c|}{ tax on emissions } & subsidy \\
\hline \hline local technology & coal & nuclear & wind & wind \\
\hline optimal policy & $\tau^{*}=33.7 E U R / t C O_{2}$ & $\tau^{*}=11.1 E U R / t C O_{2}$ & $\tau^{*}=68.8 E U R / t C O_{2}$ & $s^{*}=7.2 E U R / q_{\text {wind }}$ \\
\hline social welfare $W$ & $5.38 \times 10^{6}$ Euro $(\downarrow)$ & $11.68 \times 10^{6}$ Euro $(\downarrow)$ & $3.94 \times 10^{6} E u r o(\uparrow)$ & $2.92 \times 10^{6}$ Euro $(\downarrow)$ \\
\hline import dependence $q_{f} / Q$ & $40 \%(\uparrow)$ & $0 \%(\downarrow)$ & $25 \%(\downarrow)$ & $35 \%(\downarrow)$ \\
\hline $\mathrm{CO}_{2}$ emissions & $214340 t C \mathrm{CO}_{2}(-16 \%)$ & $0 t C \mathrm{CO}_{2}(-100 \%)$ & $31708 t C \mathrm{CO}_{2}(-41 \%)$ & $41040 t C \mathrm{O}_{2}(-24 \%)$ \\
\hline
\end{tabular}

Table 2: The optimal policy

What we learn from this simple numerical illustration is the following: firstly, coal capacity turns out to be much less attractive than in the setting without environmental damage (see Table 1) as its $\mathrm{CO}_{2}$ intensity is high. Social welfare decreases sharply and the economy becomes more vulnerable because of an increased import dependence. Thus there is a trade-off between security of supply on the one hand, and lower $\mathrm{CO}_{2}$ emissions on the other hand. Nevertheless, as regards social welfare, investing in coal capacity still remains more interesting than investing in wind power. Secondly, in a first best setting, the optimal tax $\tau^{*}$ should be equal to the marginal environmental damage $\gamma$. In our model we observe that the optimal tax is above the marginal damage. This is because the tax is not only designed to reduce emissions but also to capture part of the surplus which would otherwise go to the

\footnotetext{
${ }^{13}$ Finding the optimal solutions is not straigthforward. The full computations can be obtained from the author.
} 
exporter (see equations (20) and (21)). This leads us to the third conclusion related to the question whether one should rather tax emissions or subsidize renewables. Taxing emissions is preferred as a tax not only reduces emissions but also captures part of the surplus that would otherwise go to the exporter (in our example, the tax revenue effect even outweighs the negative effect of $\mathrm{CO}_{2}$ emissions as social welfare increases). Subsidizing wind capacity, on the other hand, reduces emissions but does not generate any additional revenue for the importing country. It can be shown that the entire subsidy expenditure is received by the importer. This last fact might also be a reason why we observe that in reality, renewable energy is often subsidized: a subsidy can be justified by technology spillover effects, which we do not consider here, but the existence of subsidies may also be the result of lobbying by the renewable energy industry. At least within our framework, taxing emissions is preferred from a social welfare point of view. However, the importer looses while citizens/tax payers gain because of less emissions and tax revenues.

This section has shown that public intervention is justified for two reasons: strategic motives and market failures. A tax on gas imports generates revenues for the importing country. Part of these revenues would otherwise add to the exporter's payoff. We have also shown that a strategic tax setting by the government and a strategic investment in local capacity by the importer are substitutes: if the local capacity is costly, the importer's bargaining power is reduced but a tax compensates for this reduced bargaining power. Of course, a tax on imports reduces the importer's payoff but this reduction is more than compensated by increased tax revenues for the importing country. If the government also cares about $\mathrm{CO}_{2}$ emissions, the optimal tax is above the marginal environmental damage since the tax contains two elements: a Pigouvian and a strategic component. Finally, while we observe in reality that renewable energy is often subsidized, we argue that a better strategy is to tax emissions instead: a subsidy increases the investment in wind power and thus reduces emissions but it does not generate any additional revenue for the importing country.

The next section extends the model to several importers and shows that another market failure, namely positive strategic spillover effects, justify public intervention.

\section{More importers}

This section questions whether or not investment incentives change if several importers bargain with the same exporter.

We consider one exporter, denoted by $e$, and two importers, $i_{1}$ and $i_{2}$. We 
assume that importers produce and sell electricity in separated regional markets $j=1,2$, i.e. demand is independent. ${ }^{14}$ To compare with the previous setting, we assume that demand in each region is fixed and equal to $Q / 2$ so that total demand $Q$ remains unchanged. We can apply this setting, for example, to the European electricity market which is still divided into different regional markets dominated by a few large electricity producers.

\subsection{Shapley Values}

Shapley values are computed for each player $h=e, i_{1}, i_{2}$ according to (1). In the setting of one exporter and one importer, negotiations were straightforward: either both players cooperate or they remain alone. With three players, more cooperation opportunities exist. As stated in Winter (2002, p.2027): „Shapley also viewed the value as an index for measuring the power of players in a game. Like a price index or other market indices, the value uses averages to aggregate the power of players in their various cooperation opportunities." The power of a player $h$ is measured by his marginal contribution $\psi_{h}(S)$ to a given coalition $S \subseteq N$. The larger his contribution, the more powerful he is. Table 3 presents every possible cooperation opportunity and the correspondent marginal contribution. For instance, in the ordering $e-i_{1}-i_{2}$, $S=\{e\}$ and the exporter's marginal contribution equals $\psi_{e}(\{e\})=v(e)-v(\emptyset)=$ $v(e)$, i.e. his stand-alone value. In the ordering $i_{2}-i_{1}-e, S=\{N\}$, he joins the two importers and his marginal contribution is $\psi_{e}(\{N\})=v(N)-v\left(i_{1}, i_{2}\right)$.

\begin{tabular}{|c|c|c|c|}
\hline ordering & marg contr $e$ & marg contr $i_{1}$ & marg contr $i_{2}$ \\
\hline \hline$e-i_{1}-i_{2}$ & $v(e)$ & $v\left(i_{1}, e\right)-v(e)$ & $v(N)-v\left(i_{1}, e\right)$ \\
\hline$e-i_{2}-i_{1}$ & $v(e)$ & $v(N)-v\left(i_{2}, e\right)$ & $v\left(i_{2}, e\right)-v(e)$ \\
\hline$i_{1}-i_{2}-e$ & $v(N)-v\left(i_{1}, i_{2}\right)$ & $v\left(i_{1}\right)$ & $v\left(i_{1}, i_{2}\right)-v\left(i_{1}\right)$ \\
\hline$i_{1}-e-i_{2}$ & $v\left(i_{1}, e\right)-v\left(i_{1}\right)$ & $v\left(i_{1}\right)$ & $v(N)-v\left(i_{1}, e\right)$ \\
\hline$i_{2}-i_{1}-e$ & $v(N)-v\left(i_{1}, i_{2}\right)$ & $v\left(i_{1}, i_{2}\right)-v\left(i_{2}\right)$ & $v\left(i_{2}\right)$ \\
\hline$i_{2}-e-i_{1}$ & $v\left(i_{2}, e\right)-v\left(i_{2}\right)$ & $v(N)-v\left(i_{2}, e\right)$ & $v\left(i_{2}\right)$ \\
\hline
\end{tabular}

Table 3: Marginal contributions in a three-player game

Assuming that the exporter's stand-alone value $v(e)$ is zero and that markets

\footnotetext{
${ }^{14}$ This assumption is also used in Inderst and Wey (2001) or Ikonnikova and Zwart (2009).
} 
are separated, i.e. $v\left(i_{1}, i_{2}\right)=v\left(i_{1}\right)+v\left(i_{2}\right)$, the Shapley values $\phi_{h}$ equal

$$
\begin{aligned}
\phi_{e} & =\frac{1}{3} \underbrace{\left[v(N)-v\left(i_{1}\right)-v\left(i_{2}\right)\right]}_{\psi_{e}(\{N\})}+\frac{1}{6}[\underbrace{\left.v\left(i_{1}, e\right)-v\left(i_{1}\right)\right]}_{\psi_{e}\left(\left\{e, i_{1}\right\}\right)}+\frac{1}{6}[\underbrace{\left.v\left(i_{2}, e\right)-v\left(i_{2}\right)\right]}_{\psi_{e}\left(\left\{e, i_{2}\right\}\right)} \\
\phi_{i_{1}} & =\frac{1}{3} \underbrace{\left[v(N)-v\left(i_{2}, e\right)\right]}_{\psi_{i_{1}}(\{N\})}+\frac{1}{6} \underbrace{v\left(i_{1}, e\right)}_{\psi_{i_{1}}\left(\left\{e, i_{1}\right\}\right)}+\frac{1}{2} \underbrace{v\left(i_{1}\right)}_{\psi_{i_{1}}\left(\left\{i_{1}\right\}\right)=\psi_{i_{1}}\left(\left\{i_{1}, i_{2}\right\}\right)} \\
\phi_{i_{2}} & =\frac{1}{3} \underbrace{\left.v(N)-v\left(i_{1}, e\right)\right]}_{\psi_{i_{2}}(\{N\})}+\frac{1}{6} \underbrace{v\left(i_{2}, e\right)}_{\psi_{i_{2}}\left(\left\{e, i_{2}\right\}\right)}+\frac{1}{2} \underbrace{v\left(i_{2}\right)}_{\psi_{i_{2}}\left(\left\{i_{2}\right\}\right)=\psi_{i_{2}}\left(\left\{i_{1}, i_{2}\right\}\right)}
\end{aligned}
$$

Expressions (28) to (30) indicate that investment decisions by one importer not only affect his own bargaining power, but also the bargaining position of the other importer.

\subsection{Analysis}

We consider the investment of importer 1, knowing that the problem of importer 2 is symmetric. Importer 1's investment affects the Shapley value of importer 2 through a change of $v(N)$ and/or of $v\left(i_{1}, e\right)$ (see equation (30)):

$$
\frac{\partial \phi_{i_{2}}}{\partial K_{1}}=\frac{\partial \psi_{i_{2}}(\{N\})}{\partial K_{1}}=\frac{1}{3}[\underbrace{C^{\prime}\left(Q-K_{i_{1}}-K_{i_{2}}\right)-r}_{\frac{\partial v(N)}{\partial K_{i_{1}}} \geq 0}-\underbrace{\left(C^{\prime}\left(\frac{Q}{2}-K_{i_{1}}\right)-r\right)}_{\frac{\partial v\left(i_{1}, e\right)}{\partial K_{i_{1}}} \geq 0}]
$$

If the marginal supply cost is constant $\left(C^{\prime \prime}\left(q_{f}\right)=0\right)$, then the investment of one importer has no effect on the other importer's bargaining position. A linear supply cost $C\left(q_{f}\right)=c q_{f}$ implies that local capacity is fully used in coalition $S=\{N\}$ and $S=\left\{i_{1}, e\right\}$ if $r<c$. If $r>c$, the local capacity is never used in these coalitions. In both cases, the external effect is zero: $\frac{\partial \phi_{i_{2}}}{\partial K_{1}}=0$. Hence, the importers' investment decisions are independent from each other. Nevertheless, there is still a strategic incentive to invest in local capacity but this is exactly the same as the problem described in Section 5. Since we are interested in interactions between investment decisions, we therefore assume a convex supply cost $C\left(q_{f}\right)=c q_{f}^{2}$.

Regarding the external effect of the investment in capacity $K_{i_{1}}$, we define 3 regions (see Appendix): 


\begin{tabular}{|c|c|c|c|}
\hline & $\frac{\partial v(N)}{\partial K_{i_{1}}}$ & $\frac{\partial v\left(i_{1}, e\right)}{\partial K_{i_{1}}}$ & $\frac{\partial \phi_{i_{2}}}{\partial K_{1}}$ \\
\hline \hline Region [1] & $2 c\left(Q-K_{i_{1}}-K_{i_{2}}\right)-r>0$ & $2 c\left(\frac{Q}{2}-K_{i_{1}}\right)-r>0$ & $\frac{2 c}{3}\left(Q / 2-K_{i_{2}}\right)>0$ \\
\hline Region [2] & $2 c\left(Q-K_{i_{1}}-K_{i_{2}}\right)-r>0$ & 0 & $2 c\left(Q-K_{i_{1}}-K_{i_{2}}\right)-r>0$ \\
\hline Region [3] & 0 & 0 & 0 \\
\hline
\end{tabular}

Table 4: Investment externalities

We notice that the external effect is always positive (region [1] and [2]) or zero (region [3]). Therefore, the investment can never hurt the other importer. However, if importers invest to maximize their own share of the total surplus, they neglect the effect of their decision on the other importer's bargaining position. Investment in local capacity $K_{i_{j}}(j=1,2)$ is suboptimal and cooperation for strategic reasons is thus required.

Figure 6 illustrates the effect of importer 1's investment in local capacity on importer 2's Shapley value, for a given investment $K_{i_{2}}$. The external effect is positive and constant in region [1] while it is positive but decreasing in region [2]. For a large capacity (region [3]), importer 1 only improves his stand-alone value $v\left(i_{1}\right)$ and the external effect is zero. The same figure also shows the effect of an increase of the critical capacity $\bar{K}$, caused by a lower variable cost $r$ of the local technology. The length of region[2] does not change while the length of region [1] increases and that of region [3] decreases. Hence, for any given level of $K_{i_{j}}(j=1,2)$, the external effect becomes larger. From this we can conclude that the external effect of local technology with a low variable cost, i.e. wind power or nuclear technology, is larger and that cooperation is especially required for these technologies.

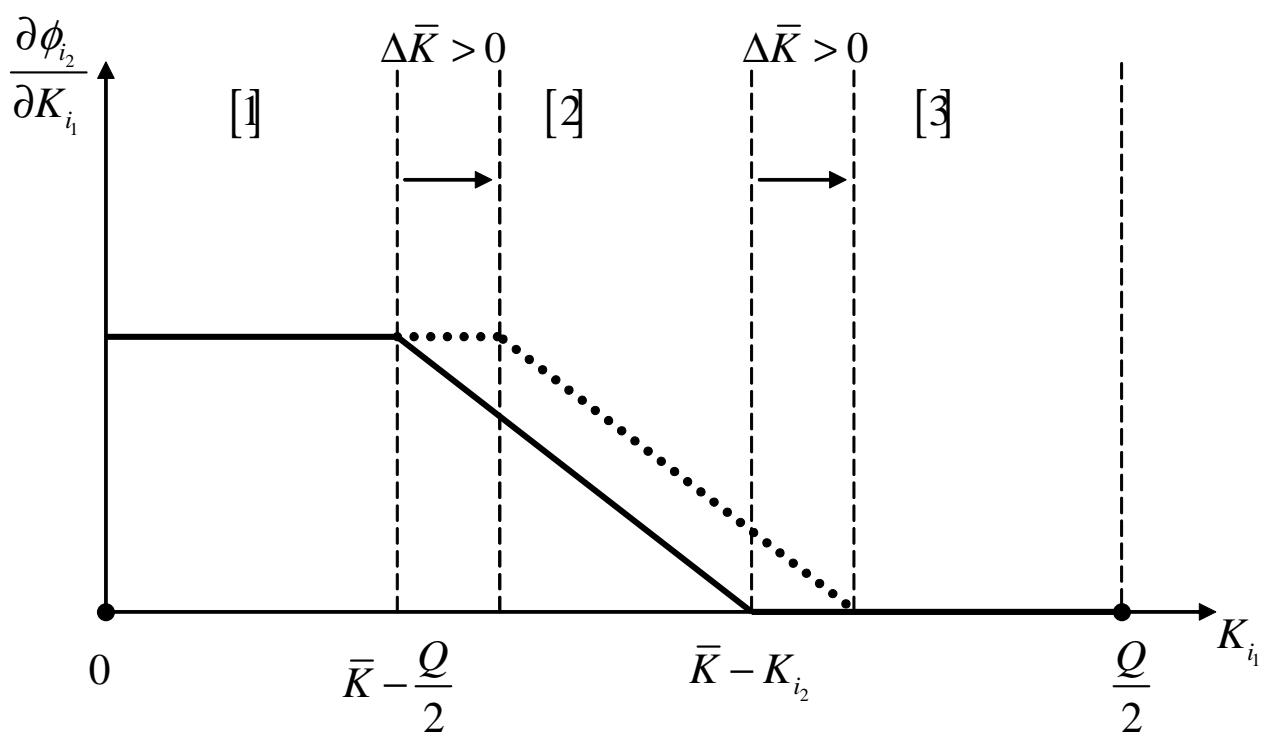

Figure 6: The external effect of investment in local generation capacity 
The reason why importer 1 affects importer 2's bargaining power is the following: If the marginal supply cost is increasing $\left(C^{\prime \prime}>0\right)$ and if the additional capacity will be used in the grand coalition $N$, importer 2 not only benefits from an increased total payoff $v(N)$ (region [1] and [2]) but the investment also reduces total demand for gas $\left(q_{f}^{1}+q_{f}^{2}\right)$ while importer 2's demand remains unchanged $\left(q_{f}^{2}=\bar{q}_{f}^{2}\right)$. Average supply costs $C\left(\bar{q}_{f}^{2}\right) / \bar{q}_{f}^{2}$ to market 2 are lower (region [1]) and the bargaining position of importer 2 improves accordingly (see Figure 7 ). For local technologies with a low variable cost $r$, both effects are relevant and the external effect is large (region [1]). For technologies with medium variable costs, investment is likely to only change the total payoff $\nu(N)$ and the external effect is postive but decreasing. For technologies with high variable costs, region [3] is large and external effects are negligible.

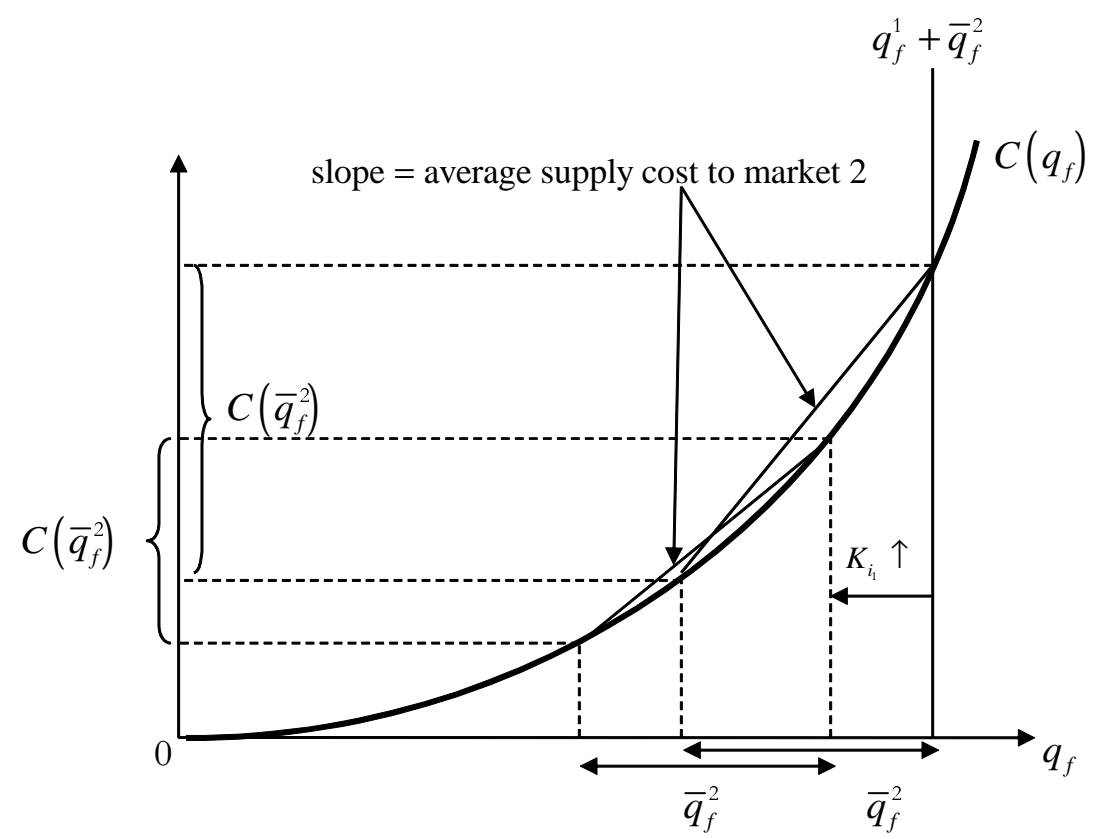

Figure 7: The average supply cost to market 2

The same reasoning holds for the effect of importer 1's investment on his own bargaining power: As long as the additional capacity is used to produce electricity, it reduces the total and his own demand for gas. Since the supply cost of gas is convex, the average supply cost decreases and his bargaining power increases. Hence, the channel through which an importer obtains a better deal is a reduced demand combined with a convex supply cost. This insight is in line with Inderst and Wey (2007) where total demand is given and a larger firm gets a better deal as the average supply cost to this firm is lower. Here, the firm's size does not change while total demand and its own demand decreases. Of course, independent of whether the additional capacity is used or not, importer 1 also increases his bargaining power 
through a higher stand-alone value $v\left(i_{1}\right)$.

\section{Conclusion}

We have shown that a private company invests in local technology to improve its bargaining position with respect to a monopolistic supplier of an input such as gas. Hence, the importer does not act as a passive price-taker since he knows that he can get more favorable terms by improving his outside option. As a matter of fact, the negotiated gas price is a decreasing function of the investment in local capacity. We may even observe that there is more investment than that which is needed for electricity production, especially if the capacity cost is relatively low. This unused capacity only has a threatening role.

Public intervention in importing countries is justified for two reasons: strategic motives and market failures. With a tax on gas, the government captures part of the surplus that would otherwise go to the exporter. We have also shown that a strategic tax setting by the government and strategic investment in local capacity by the importer are alternative measures to get a larger part of the surplus. The cheaper the local technology, the lower the optimal tax level. A costly local technology reduces the importer's bargaining power and a tax on gas imports compensates for this reduced bargaining power. Taxing emissions is also a way to correct the negative externality implied by harmful $\mathrm{CO}_{2}$ emissions. Therefore, the optimal tax level has two components: a Pigouvian component and a strategic component.

The numerical illustration shows that when taxing emissions, coal capacity becomes much less attractive as welfare sharply decreases and the import dependence increases. In this case, there is therefore a trade-off between environmental protection and security of supply. Investing in nuclear technology, on the other hand, is always the best option. However, building new nuclear plants will be subject to public opposition.

Investing in wind capacity is less attractive for the importer since the fixed cost is high. To reduce emissions, it is better to tax emissions instead of subsidizing electricity generation based on wind capacity as the tax will capture part of the surplus that would otherwise go to the exporter. With a subsidy, no additional revenue is generated for the importing country.

With a model of 2 importers bargaining with the same exporter, there are positive strategic externalities of investments in local technologies if the marginal supply cost of gas is increasing. If every importing country only considers its own strategic position, investment is likely to be suboptimal when considering their joint surplus. 
Externalities are more pronounced for technologies with a low variable cost. A common European energy policy, such as setting RES targets, can therefore make sense from a strategic point of view. If, on the other hand, we assume that the marginal supply cost of gas is constant, there are no strategic externalities while it can remain interesting from a strategic point of view to invest in local capacity.

\section{References}

[1] Awerbuch, S. 2006. „Portfolio-based electricity generation planning: policy implications for renewables and energy security." Mitigation and Adaption Strategies for Global Change, 11: 693-710.

[2] Bar-Lev, D., and S. Katz. 1976. „A portfolio approach to fossil fuel procurement in the electric utility industry." The Journal of Finance, 31(3): 933-947.

[3] Dobson, P. W., and M. Waterson. 1997. „Countervailing power and consumer prices." The Economic Journal, 107(441): 418-430.

[4] European Commission. 1999. „ExternE: Externalities of energy.” Vol.8: Global Warming.

[5] European Commission. 2008. „20 20 by 2020 - Europe's climate change opportunity." $\operatorname{COM}(2008) 30$ final.

[6] Galbraith, J.K. 1952. American capitalism: The concept of countervailing power. Boston: Houghton Mifflin.

[7] Goulder, L., D. Parry, and D. Burtraw. 1997. "Revenue-raising vs. other approaches to environmental protection: the critical significance of pre-existing tax distortions." RAND Journal of Economics, 28(4): 708-731.

[8] Ikonnikova, S., and G. Zwart. 2009. „Strengthening buyer power on the EU gas market: Import caps and supply diversification." Working Paper, presented on EARIE Conference 2009.

[9] Inderst, R., and G. Schaffer. 2008. „Buyer power in merger control.” In Issues in Competition Law and Policy, chap.XX, ed. W.D. Collins, ABA Antitrust Section Handbook.

[10] Inderst, R., and C. Wey. 2007. „Buyer power and supplier incentives.” European Economic Review, 51: 647-667. 
[11] International Energy Agency (IEA). 2005. Projected costs of generating electricity - 2005 update. Organization for Economic Co-Operation and Development (OECD).

[12] Karp, L., and D.M. Newberry. 1992. „Dynamically consistent oil import tariffs." The Canadian Journal of Economics, 25(1): 1-21.

[13] Liski, M. and O. Tahvonen. 2004. "Can carbon tax eat OPEC's rents?" Journal of Environmental Economics and Management, 47:1-12.

[14] Mansur, E.T. 2007. "Prices vs. quantities: environmental regulation and imperfect competition." NBER Working Paper Series, WP 13510, October.

[15] Nash, J. 1950. The bargaining problem. Econometrica, 18(2): 155-162.

[16] Pérez-Castrillo, D., and D. Wettstein. 2001. „Bidding for the surplus: a non-cooperative approach to the Shapley value." Journal of Economic Theory, 100: $274-294$.

[17] Rapoport, A. 1970. N-Person game theory - concepts and applications. Dover Publications, New York.

[18] Roques, F.A., D.M. Newbery, and W.J. Nuttall. 2008. „Fuel mix diversification incentives in liberalised electrricity markets: a mean-variance portfolio theory approach." Energy Economics, 30(4): 1831-1849.

[19] Rubio, S.J. and L. Escriche. 2001. "Strategic pigouvian taxation, stock externalities and polluting non-renewable resources." Journal of Public Economics, 79(2): 297-313.

[20] Shapley, L.S. 1953. "A value for n-person games." In Contributions to the Theory of Games, vol. 2, pp. 307-317, eds. H. Kuhn and A.W. Tucker, Princeton: Princeton University Press.

[21] Tahvonen, O. 1996. "Trade with polluting nonrenewable resources." Journal of Environmental Economics and Management, 30(1): 1-17.

[22] von Ungern-Sternberg, T.. 1996. „Countervailing power revisited.” International Journal of Industrial Organization, 14: 507-520.

[23] Weitzman, M.L. 1974. "Prices vs. quantities." Review of Economic Studies, 41(4): 477-491. 
[24] Wickart, M., and R. Madlener. 2007. „Optimal technology choice and investment timing: a stochastic model of industrial cogeneration vs. heat-only production." Energy Economics, 29(4): 934-952.

[25] Winter, E. 2002. „The Shapley Value.” in Aumann, R.J. and S. Hart (Eds.): Handbook of game theory wih economic applications (Vol 3), Elsevier Science.

[26] Wirl, F., and E. Dockner. 1995. "Leviathan governments and carbon taxes: costs and potential benefits." European Economic Review, 39(6): 1215-1236.

\section{Appendix}

\section{The cooperative payoff in the linear case}

The maximization problem

$$
\begin{gathered}
\max _{q_{f}, q_{l}}\left[(\bar{P}-c) q_{f}+(\bar{P}-r) q_{l}\right] \\
\text { subject to } \begin{cases}q_{f}+q_{l} & =Q \\
q_{l} & \leq K\end{cases}
\end{gathered}
$$

can be rewritten as

$$
\max _{q_{l}}\left[(\bar{P}-c)\left(Q-q_{l}\right)+(\bar{P}-r) q_{l}+\lambda_{K}\left(K-q_{l}\right)\right]
$$

where $\lambda_{K}$ is the multiplier associated to the restriction $q_{l} \leq K$. The optimal solution $q_{l}^{*}$ to this problem has to satisfy the following Kuhn-Tucker conditions:

1. $q_{l} \geq 0$

2. $c-r-\lambda_{K} \leq 0$

3. $q_{l}\left(c-r-\lambda_{K}\right)=0$;

4. $\lambda_{K} \geq 0$

5. $K-q_{l} \geq 0$

6. $\lambda_{K}\left(K-q_{l}\right)=0$.

These conditions imply two cases:

$c-r>0$. The condition $q_{l} \leq K$ is binding $\left(\lambda_{K}>0\right)$ and $q_{l}^{*}=K$. Therefore, the capacity is fully used and $q_{f}^{*}=Q-K$. 
$c-r \leq 0$. The condition $q_{l} \leq K$ is not binding $\left(\lambda_{K}=0\right)$ and $q_{l}^{*}=0$. Consequently, $q_{f}^{*}=Q$.

\section{Applying the Shapley value}

The Shapley value allocates the surplus of the grand coalition (the set of all players) according to the average marginal contribution of every player. The average marginal contribution of a player is obtained by considering every possible ordering of the grand coalition and by taking the average of the marginal effect a player has by joining the coalition.

Since we have two players, there are two orderings possible: $i-e$ and $e-i$. The marginal contribution of the importer in the first ordering is equal to $v(i)-v(\emptyset)=$ $v(i)$ if we assume that the value $v(\emptyset)$ of an empty set $\emptyset$ is zero. The marginal contribution in the second ordering is $(v(N)-v(e))$. Therefore the Shapley value of the importer is equal to

$$
\phi_{i}=\frac{1}{2}[v(N)-v(e)+v(i)]
$$

or

$$
\phi_{i}=\frac{1}{2}[v(N)]+\frac{1}{2}[v(i)-v(e)] .
$$

For the Shapley value of the exporter, we proceed in the same way and get

$$
\phi_{e}=\frac{1}{2}[v(N)]+\frac{1}{2}[v(e)-v(i)]
$$

\section{Equivalence between the Shapley value and the Nash Bar- gaining Solution}

In the two-person bargaining problem of this paper, we show that the sharing of the total surplus $v(N)$ implied by the Shapley value is equivalent to the sharing described by the Nash Bargaining Solution (Nash, 1950).

Both the Shapley value (SV) and the Nash Bargaining Solution (NBS) satisfy the efficiency axiom: the players' payoffs sum up to the value of the grand coalition $v(N)$. Thus the sharing point lies on the efficient frontier of the set of possible outcomes $S$. If no agreement is reached, then every player gets the stand-alone value. The disagreement point is therefore $D=\{v(i), v(e)\}=\{v(i), 0\}$.

The Nash Bargaining Solution implies a sharing $\left(\alpha_{i}, 1-\alpha_{i}\right)$ of the total surplus 
$v(N)$ that maximizes:

$$
\left[\alpha_{i} v(N)-v(i)\right]\left[\left(1-\alpha_{i}\right) v(N)-0\right]
$$

where $\alpha_{i} \epsilon[0,1]$ is the share of the surplus $v(N)$ that the importer receives. The first-order condition implies a share

$$
\alpha_{i}^{*}=\frac{v(N)-(v(e)-v(i))}{2 v(N)}
$$

In our setting, the Nash Bargaining Solution proposes a sharing equivalent to equation (31) and (32). Note that the importer's investment in local technology affects $v(N)$, the disagreement point $D$ and, therefore, the set of possible outcomes $S$. Improving the outside option $v(i)$ increases the importer's bargaining power and, hence, his share of the total surplus $\left(d \alpha_{i}^{*} / d v(i)>0\right)$. The graphical solution is presented below.

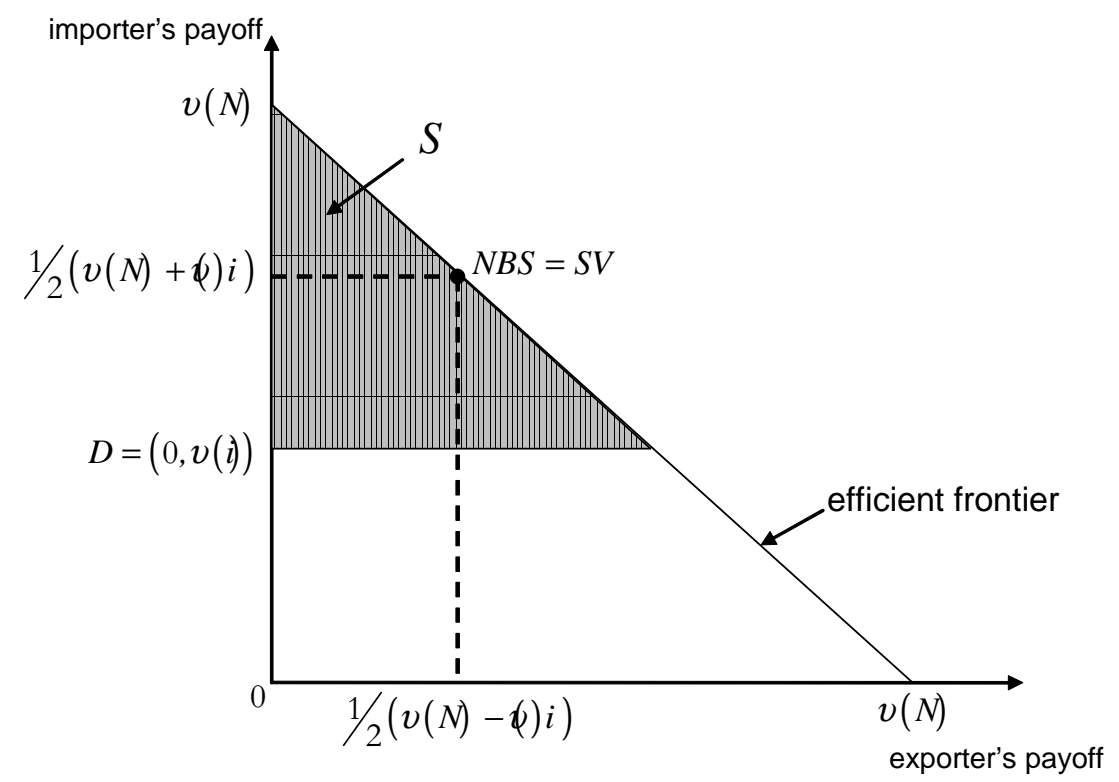

Figure 8: The Shapley Value and the Nash Bargaining Solution

\section{The cooperative payoff in the non-linear case}

The maximization problem

$$
\max _{q_{f}, q_{l}}\left[\bar{P}\left(q_{f}+q_{l}\right)-r q_{l}-C\left(q_{f}\right)\right]
$$




$$
\text { subject to } \begin{cases}q_{f}+q_{l} & =Q \\ q_{l} & \leq K\end{cases}
$$

can be rewritten as

$$
\max _{q_{l}}\left[\bar{P} Q-r q_{l}-c\left(Q-q_{l}\right)^{2}+\lambda_{K}\left(K-q_{l}\right)\right]
$$

where $\lambda_{K}$ is the multiplier associated to the restriction $q_{l} \leq K$. The optimal solution $q_{l}^{*}$ to this problem has to satisfy the following Kuhn-Tucker conditions:

1. $q_{l} \geq 0$;

2. $-r+2 c\left(Q-q_{l}\right)-\lambda_{K} \leq 0$

3. $q_{l}\left(-r+2 c\left(Q-q_{l}\right)-\lambda_{K}\right)=0$;

4. $\lambda_{K} \geq 0$;

5. $\left(K-q_{l}\right) \geq 0$;

6. $\lambda_{K}\left(K-q_{l}\right)=0$.

Not surprisingly, $q_{l}^{*}$ depends on the available capacity $K$. We distinguish two cases:

if $\mathbf{K} \leq \mathbf{Q}-\frac{\mathbf{r}}{\mathbf{2 c}}=\overline{\mathbf{K}}$, then $q_{l}^{*}=K$ (the capacity constraint is binding, $\lambda_{K}>0$ ) and $q_{f}^{*}=Q-K$.

if $\mathbf{K}>\mathbf{Q}-\frac{\mathbf{r}}{\mathbf{2 c}}=\overline{\mathbf{K}}$, then $q_{l}^{*}=\bar{K}$.

\section{Two importers}

This section analyzes the effect of the investment of importer 1 on the payoff of the grand coalition, $v(N)$, and the payoff $v\left(i_{1}, e\right)$. The combined effect also determines the effect of importer 1's investment on importer 2's Shapley value (equation 30). Note that the effect on the stand-alone value $v\left(i_{1}\right)$ is positive as long as $K_{i_{1}} \leq Q / 2$ and $K_{i_{1}}$ will never exceed the size of the market $Q / 2$ as it has no effect on the Shapley value $\phi_{i_{1}}$. We assume the supply cost to be convex, $C\left(q_{f}\right)=c q_{f}^{2}$.

\section{Effect on $v(N)$}

Importer 1's investment has no effect on the payoff of the grand coalition if $K_{i_{1}}+$ $K_{i_{2}}>\bar{K}=Q-r / 2 c$. The surplus cannot be increased since the supply cost of an additional unit of gas is lower than the variable cost of the local capacity if $K_{i_{1}}+K_{i_{2}}$ exceeds the critical capacity $\bar{K}: 2 c q_{f}<r$. Accordingly, the effect will be positive if 
$K_{i_{1}}+K_{i_{2}}<\bar{K}$ since the variable cost $r$ is lower than the marginal supply cost of gas, $2 c q_{f}$.

Effect on $v\left(i_{1}, e\right)$

The investment of importer 1 will not anymore increase the payoff of the coalition $S=\left\{i_{1}, e\right\}$ if the marginal supply cost of gas is lower than the variable cost of the local capacity, i.e. if $K_{i_{1}}>\bar{K}-Q / 2$. This implies that the effect is zero as long as the critical capacity is small, i.e. if $\bar{K}<Q / 2$.

The table below presents the impacts that the investment of importer 1 may have on $v(N)$ and $v\left(i_{1}, e\right)$.

\begin{tabular}{|l|c|c|}
\hline & $\frac{\partial v\left(i_{1}, e\right)}{\partial K_{i_{1}}}=0$ & $\frac{\partial v\left(i_{1}, e\right)}{\partial K_{i_{1}}}>0$ \\
\hline$\frac{\partial v(N)}{\partial K_{i_{1}}}=0$ & $\bar{K}<K_{i_{1}}+K_{i_{2}}$ & impossible \\
\hline$\frac{\partial v(N)}{\partial K_{i_{1}}}>0$ & $K_{i_{1}}+K_{i_{2}}<\bar{K}<K_{i_{1}}+Q / 2$ & $\bar{K}>K_{i_{1}}+Q / 2$ \\
\hline
\end{tabular}

Depending on the effect of the investment $K_{i_{1}}$ on $v(N)$ and $v\left(i_{1}, e\right)$, we define 3 regions:

1. $K_{i_{1}} \leq \bar{K}-Q / 2: \frac{\partial v(N)}{\partial K_{i_{1}}}>0$ and $\frac{\partial v\left(i_{1}, e\right)}{\partial K_{i_{1}}}>0$

2. $\bar{K}-Q / 2<K_{i_{1}}<\bar{K}-K_{i_{2}}: \frac{\partial v(N)}{\partial K_{i_{1}}}>0$ and $\frac{\partial v\left(i_{1}, e\right)}{\partial K_{i_{1}}}=0$

3. $K_{i_{1}} \geq \bar{K}-K_{i_{2}}: \frac{\partial v(N)}{\partial K_{i_{1}}}=0$ and $\frac{\partial v\left(i_{1}, e\right)}{\partial K_{i_{1}}}=0$ 
Copyright ( 2010 @ the author(s). Discussion papers are in draft form. This discussion paper is distributed for purposes of comment and discussion only. It may not be reproduced without permission of the copyright holder. Copies of working papers are available from the author. 